\title{
Continuous EB Welding of the Reinforcement of the CMS Conductor
}

\author{
R. Folch, B. Blau, D. Campi, R. Christin, J. P. Créton, B. Curé, A. Hervé, I. L. Horvath, J. Neuenschwander, \\ P. Riboni, S. Sequeira Tavares, and S. Sgobba
}

\begin{abstract}
The Compact Muon Solenoid (CMS) is one of the general-purpose detectors to be provided for the LHC project at CERN. The design field of the CMS superconducting magnet is $4 \mathrm{~T}$, the magnetic length is $12.5 \mathrm{~m}$ and the free bore is $6 \mathrm{~m}$.

In order to withstand the electro-mechanical forces during the operation of the CMS magnet, the superconducting cable embedded in a $99.998 \%$ pure aluminum matrix is reinforced with two sections of aluminum alloy EN AW-6082 assembled by continuous Electron Beam Welding (EBW). A dedicated production line has been designed by Techmeta, a leading company in the field of EBW.

The production line has a total length of $70 \mathrm{~m}$. Non-stop welding of each of the 20 lengths of $2.5 \mathrm{~km}$, required to build the coil, will last 22 hours.

EBW is the most critical process involved in the production line. The main advantage of the EBW process is to minimize the Heat Affected Zone; this is particularly important for avoiding damage to the superconducting cable located only $4.7 \mathrm{~mm}$ from the welded joints. Two welding guns of $20 \mathrm{~kW}$ each operate in parallel in a vacuum chamber fitted with dynamic airlocks. After welding, the conductor is continuously machined on the four faces and on each corner to obtain the required dimensions and surface finish.

Special emphasis has been put on quality monitoring. All significant production parameters are recorded during operation and relevant samples are taken from each produced length for destructive testing purposes. In addition, a continuous phased array ultrasonic checking device is located immediately after the welding unit for the continuous welding quality control, along with a dimension laser measurement unit following the machining.
\end{abstract}

Index Terms-CMS magnet conductor, critical current, electron beam welding, reinforced superconducting cable.

\section{INTRODUCTION}

$\mathbf{T}$ HE DESIGN of the superconducting coil of the CMS magnet has its most distinctive feature in the self supporting structure of its conductor.

In most of the existing large magnets the hoop strength is provided by an aluminum alloy cylinder, which contains the winding.

For the CMS solenoid, with 4 layers of conductor, such a solution would have led to a $190 \mathrm{~mm}$ thick cylinder to limit the strain at $0.15 \%$. The total axial force of $147 \mathrm{MN}$ would have

Manuscript received September 24, 2001.

R. Folch, D. Campi, B. Curé, A. Hervé, S. Sequeira Tavares, and S. Sgobba are with CERN, Geneva, Switzerland (e-mail: Ramon.Folch@cern.ch).

B. Blau, I. L. Horvath, and P. Riboni are with the Swiss Federal Institute of Technology (ETH), Zürich, Switzerland.

R. Christin and J. P. Créton are with TECHMETA, Techniques Métallurgiques Avancées, Tessy, France.

J. Neuenschwander is with the Swiss Federal Laboratories for Materials

Testing and Research (EMPA), Dübendorf, Switzerland.

Publisher Item Identifier S 1051-8223(02)03566-2.

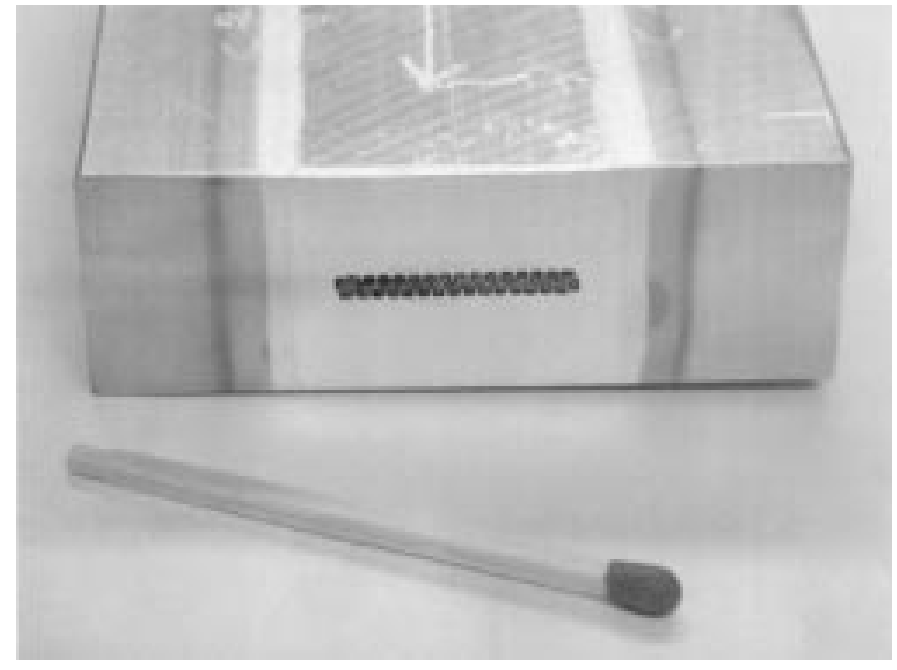

Fig. 1. Cross section of the electron beam welded CMS conductor.

been transmitted to the external cylinder through the bonding of the insulation of the outermost layer and the Aluminum Alloy cylinder. This was considered too risky.

In addition the axial thermal contraction of the pure aluminum package would not have matched the contraction of the Aluminum Alloy cylinder adding further shear stress.

The local reinforcement of the conductor avoids all these problems. A description of the conductor and its components are reported in [1]-[3].

Different solutions to reinforce the conductor have been studied and in particular:

- The co-extrusion of the Aluminum Alloy reinforcement around the insert.

- The soft soldering of the reinforcement.

- The electron beam welding technique to join the reinforcement to the insert.

An R\&D program was financed by CERN in 1993 to investigate the three options.

The co-extrusion had to be abandoned due the extrusion temperature of the reinforcement, which had to be higher than the one of pure Aluminum leading to an unacceptable degradation of the NbTi superconductor.

The soft soldering technique was possible for laboratory lengths and has been kept until the final decision as the back up solution.

The electron beam welding has been chosen as the most elegant and the one that limited at the very minimum the thermal impact, minimizing the degradation of the superconducting strands. Fig. 1 shows a cross section of the EBW conductor. 
TABLE I

EB Welding Parameters During the $1000 \mathrm{~m}$ ACCEPTANCE Test

\begin{tabular}{lcc}
\hline & EB Gun 1 & EB Gun 2 \\
Enclosure vacuum & \multicolumn{2}{c}{$2.5810^{-2} \mathrm{mbar}$} \\
Gun voltage & $45.0 \mathrm{kV}$ & $44.8 \mathrm{kV}$ \\
Gun current & $401.5 \mathrm{~mA}$ & $381.0 \mathrm{~mA}$ \\
Focusing current & $1.65 \mathrm{~A}$ & $1.54 \mathrm{~A}$ \\
Beam residual current & $30.4 \mathrm{~mA}$ & $52.4 \mathrm{~mA}$ \\
\hline
\end{tabular}

The first samples of conductor reinforced by EBW were produced in the CERN Central workshop within the framework of a study managed by ETHZ [4].

For the full production of the conductor a continuous process had to be defined to produce 20 unit lengths of $2.5 \mathrm{~km}$ each.

More details on the CMS magnet are reported in [5].

\section{PROCESS DESCRIPTION}

The features of the Electron Beam Welding technique are:

- an extremely high power density at the focus distance (hundreds $\mathrm{kW} / \mathrm{mm}^{2}$ ), the energy transfer occurs efficiently within the work piece,

- a high welding speed resulting in a narrow weld and heat affected zone,

- highly reproducible and consistent welding parameters assuring a uniform quality of the welds.

The process is optimized for operation under vacuum; a weld pool fully protected from oxidation compensates for this apparent complication.

Electrons emitted by a high temperature material, the cathode, are accelerated by the HV provided by an anode and then focused and directed by magnetic fields onto the target; the devices producing the beam, the electron guns, (EG) used in our application have a power of the order of $20 \mathrm{~kW}$. The main welding parameters used in operation are summarized in Table I. EB Gun 1 is located $850 \mathrm{~mm}$ upstream respect to EB Gun 2. The preheating effect of EB Gun 1 leads to lower values for EB Gun 2 beam current.

They are almost out-of-the-shelf devices produced by Techmeta, which have been chosen, between other reasons, because the source of electrons, the cathode is a massive ring heated by a tungsten filament. This solution assures a wider life span than the usual solution which uses directly the electrons produced by the filament. A further advantage of the Techmeta EG is its insensitivity to the "flashes": in the welder's jargon, the disruption of the HV fields (a sort of spark) leading to a loss of the beam.

The actual construction is very similar to the conceptual design of the line described in the technical specification of the production line. The full process for assembling the inner part of the conductor to the two reinforcement sections by EBW can be grouped into 4 main operational blocks; the handling and management of the components and final conductor, the EBW itself, the machining of the assembled parts, the overall control system.

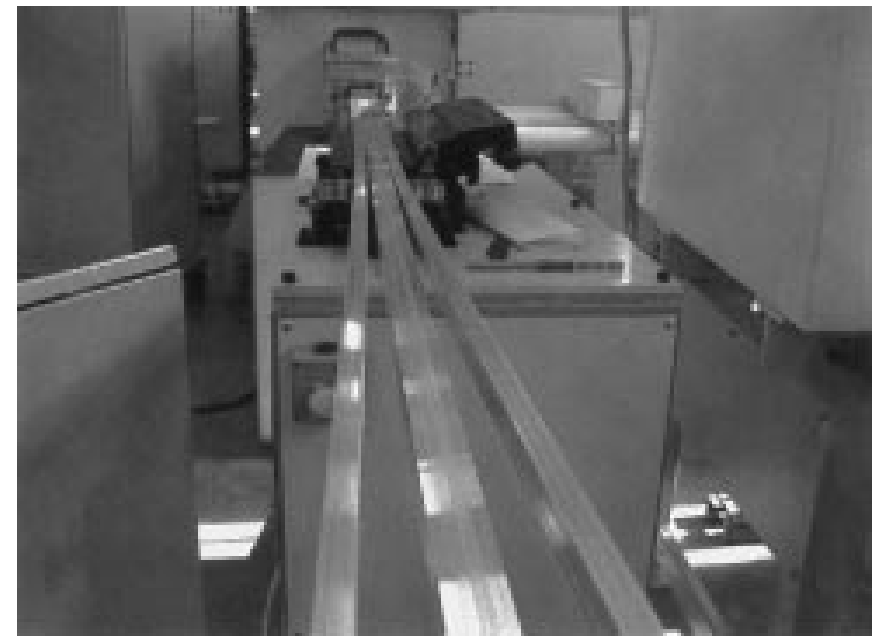

Fig. 2. View of the insert and the two reinforcements sections entering into the EB welding unit at a feed speed of $2 \mathrm{~m} / \mathrm{min}$.

Handling of the components and conductor includes spooling and despooling of the bars, pre-straightening and straightening, their movement being driven by a caterpillar with rolls, cleaning of the bars, sampling and joining of the bars from one length to the other.

The EBW encompasses the precise alignment of the components inside the vacuum envelope, the production of vacuum for both the welding tank and the airlocks, the management of the material sputtered around the tank during operation, parameters monitor and control, and finally a welding quality monitoring by ultrasonic inspection. Fig. 2 shows the three components entering into the EB welding unit.

The machining unit includes activities such as the management of the chips, dimensional checks in addition; of course, of the milling itself performed by high-speed diamond milling tools.

The overall control system integrates all commands, signals, and alarms coming from the dedicated consoles or control unit of the line except for the US inspection unit and the Measuring unit. The basic policy of the operation is to monitor the entire operation automatically; man intervention is triggered by alarm signals with two level of gravity; a first level imposes the attention of the operator and his ok for continuing the operation; a second level of alarm, is tuned at values which will trigger the stop of the line even before any human intervention or judgment.

An additional facility embedded into the system is the capacity of the line to reprocess an entire conductor length, should this be necessary.

The uniqueness of the line resides in its capability to handle a product, the conductor, by far much more massive than any other continuously welded products, essentially thin bimetal strips; the uninterrupted length is also quite unusual.

\section{Test And Results of Metallurgical Examinations}

During the tuning of the welding parameters, metallurgical examinations have been systematically performed. Unlike to the on-line US checking, these examinations require destructive testing on samples cut from the conductor. For preliminary 
assessment the manufacturer extracted local samples from the welded conductor without the need to cut all over the cross section of the conductor. Macrographs of these samples allow to check the width of the weld seam and to get a general view of the shape of the weld seam.

From the results of the first campaign of metallurgical examinations made on samples of $2 \mathrm{~mm}$ weld width, the following defects could be noticed:

- Transversal cracks (due to liquation effect).

- Porosities (mainly due to lack of cleanliness of the components).

- Groove on the root of the weld seam due to lack of material (much more noticeable on weld seam of the second gun that sees colder components).

Presence of transversal cracks could be minimized by reducing the width of the weld seam. However, to have the bottom groove disappearing after machining it was required to increase the width of the weld.

Considering that there is no risk of crack propagation under the conditions of use in the CMS coil application, priority was given to minimize the groove by enlarging the weld width up to a maximum of $2.5 \mathrm{~mm}$. As a consequence, the distance between the weld seam and the Rutherford cable is reduced. However, according to the results of the critical current tests, no degradation of the superconducting properties seems to be produced by the EBW operation.

So far, $4 \mathrm{~km}$ of conductor under such welding conditions have been produced. The macro and micro examinations on the samples show a weld width of 2.1 to $2.3 \mathrm{~mm}$ and a minimum distance between weld and sc. cable of $3.4 \mathrm{~mm}$.

In addition to the metallurgical examinations, mechanical tests of the weld joints have been performed, such as tensile test and shear test. In all cases, the results are far above requirements.

\section{ULTRASONIC MONITORING}

Ultrasonic is a well-known method to inspect the quality of welds. In a previous study [6] we demonstrated the applicability of ultrasonic imaging to detect non welded regions of in EB welded samples. Mechanical scanning, however, is far too slow to inspect $\mathrm{km}$-long conductors. Due to the successful use of the ultrasonic phased-array technology to the bond check of superconducting cables during co-extrusion, we have set-up a second system which allows the continuous control of the electron beam welding seams. A detailed description of the ultrasonic system used for the on-line quality assurance of the CMS conductor can be found in [7].

Two 64-element probes $(11 \mathrm{MHz})$ are placed on each side of the CMS conductor inspecting both welded zones. Probes and conductor are immersed in water. The amount of ultrasonic reflection from the interface reinforcement/insert gives a measure of the bond quality. The probe's sound beam moves meander-like over the conductor, across the conductor by electronic scanning and in the length direction by the production itself. The result is a C-scan, which is a two-dimensional plot of the echo amplitude measured within a defined gate. Good welding results in small amplitude. However, if a bad welding
TABLE II

COMPARISON OF STRAND CRITICAL CURRENT DEGRADATIONS FOR MAIN CONDUCTOR MANUFACTURING STEPS

\begin{tabular}{lrl}
\hline$I c$ in A, at 4.2 K, 5 T & Mean Ic & \multicolumn{1}{c}{ Degradation } \\
Strand in virgin state & $1979 \mathrm{~A}$ & - \\
Strand after co-extrusion & $1862 \mathrm{~A}$ & $5.9 \%$ compared to virgin strand \\
Strand after EBW & $1839 \mathrm{~A}$ & $\begin{array}{l}1.3 \% \text { compared to extruded strand } \\
\end{array}$ \\
& & $7.1 \%$ compared to virgin strand \\
\hline
\end{tabular}

is present, then the echo has a large amplitude. A highly sophisticated software allows the on-line monitoring of the welding quality during production.

The testing unit is placed directly after the electron beam welding unit, i.e., the nonmachined conductor is inspected. A total amount of about $5 \mathrm{~km}$ of electron beam welded CMS conductor has been tested up to now. Special test welds were produced, for which different reduced electron beam energies were applied to provoke localized weld defects. On such samples we could verify that the ultrasonic phased-array technique clearly discriminates between good welding and bad welding. During the production of the $2.5 \mathrm{~km}$ prototype length the ultrasonic control clearly indicated that the welding between reinforcement sections and insert was generally of very good quality.

\section{Tests of Conductor After EB Welding}

In order to qualify and approve the welding operation set of parameters, the electrical properties of the superconducting cable following the EBW operation shall be investigated. Electrical tests were performed on short conductor samples to check the critical current. Measurements of critical current under an external field of $5 \mathrm{~T}$ were carried out by the CMS collaboration at CEA/Saclay (France) and INFN Genova (Italy). At CEA/Saclay the critical current is measured on strands extracted from the Rutherford cable, after machining the conductor reinforcement and etching the pure aluminum stabilizer. Strand samples are cooled down at $4.2 \mathrm{~K}$ and connected through cryogenic current leads to a power supply. INFN Genova measures the critical current on a full insert by inducing current in a ring shaped sample that acts as the secondary of a superconducting coil [8].

With the production parameters as set by the manufacturer (see Table I), the degradation of the critical current due to EBW is kept to a minimum, of the order of $1-2 \%$ (see Table II), i.e., inside the critical current measurement accuracy. Therefore it is not possible to conclude that a degradation of the critical current is observed. Hence the EBW degradation is negligible. These measurements confirm the results of the CERN preliminary EBW test program [4].

The EBW line was also qualified for an emergency stop. In such a case, the power of the electron guns is switched off before the line stops completely with some inertia. To come to a total stop takes about $500 \mathrm{~ms}$. The line can be re-started when the fault reset is done, provided the conductor has cooled down. Samples were manufactured with a re-start at full EBW power, but also by ramping up this power progressively to its nominal value. Measurements from both CEA and INFN show that 
the degradation is negligible on the samples tested, again about $1-2 \%$. Nevertheless, some more tests are being carried out to get a better statistics.

To conclude, the EBW operation is fully satisfactory concerning the electrical properties of the conductor.

\section{QUALITY ASSURANCE}

As required by the technical specification Techmeta has been qualified according to ISO 9002 Quality Assurance requirements.

However, in addition, a specific quality assurance follow-up system has been implemented for the production of the 21 conductor lengths. The management tool used is EDMS (Engineering Data Management System) in which all production records and sample test reports are archived. The key document is the Traveler. It contains all the useful data concerning the conductor length that will be required downstream for the production of the CMS coil, such as:

- Conductor length.

- Identification of the welded components.

- Quality aspect important points.

In order to monitor and record the production parameters the production line has been equipped with a dedicated data acquisition system. The value of each of the following parameters is recorded every $500 \mathrm{~ms}$ (each $16.5 \mathrm{~mm}$ at $2 \mathrm{~m} / \mathrm{min}$ ):

- Production speed.

- Conductor length.

- Pulling force.

- Enclosure vacuum level.

- Width of the reinforcement sections.

And for each of the two EB Guns:

- Gun voltage.

- Gun current.

- Focusing current.

- Beam residual current.

The monitoring of the quality of the welding between the pure aluminum and the reinforcement as well as the dimensions of the cross section of the conductor is ensured by independent devices under the control of ETHZ.

During the production, a set of samples will be taken at the beginning and at the end of each one of the remaining 20 conductor lengths. Some will be used for mechanical test and others will be kept for metallurgical and degradation tests.

So far, all the acceptance tests of the line have been performed. A test protocol for each length has been established and archived together with all the relevant test reports. The first $2.5 \mathrm{~km}$ in real conditions has been produced early September. The corresponding samples are under examination.

\section{REFERENCES}

[1] B. Curé, B. Blau, D. Campi, L. F. Goodrich, I. L. Horvath, F. Kircher, R. Liikamaa, J. Seppälä, R. P. Smith, J. Teuho, and L. Vieillard, "The superconducting strand for the CMS solenoid conductor," IEEE Trans. Appl. Superconduct., submitted for publication.

[2] S. Sequeira Tavares, B. Blau, D. Campi, B. Curé, I. L. Horvath, P. Riboni, S. Sgobba, and R. P. Smith, "Auminium alloy production for the reinforcement of the CMS conductor," IEEE Trans. Appl. Superconduct., submitted for publication.

[3] B. Blau, D. Campi, B. Curé, R. Folch, A. Hervé, I. L. Horvath, F. Kircher, R. Musenich, J. Neuenschwander, P. Riboni, S. Sgobba, S. Sequeira Tavares, and R. P. Smith, "The CMS conductor," IEEE Trans. Appl. Superconduct., submitted for publication.

[4] I. L. Horvath, F. Wittgenstain, F. Bertinelli, A. Desirelli, S. Sgobba, T. Tardy, D. Fritz, and J. Neuenschwander, "Manufacture of aluminum stabilised and reinforced superconductors by electron beam welding technique,", Oct. 20, 1997.

[5] A. Hervé, G. Acquistapace, D. Campi, P. Cannarsa, P. Fabbricatore, F. Feyzi, H. Gerwig, J. P. Grillet, I. L. Horvath, V. Kaftanov, F. Kircher, R. Loveless, J. M. Maugain, G. Perinic, H. Rykaczewski, E. Sbrissa, R. P. Smith, and L. Veillet et al., "Status of the CMS magnet," IEEE Trans. Appl. Superconduct., submitted for publication.

[6] J. Neuenschwander, Th. Lüthi, I. L. Horvath, and V. Pasquer, "Ultrasonic testing of aluminum stabilised high-current superconducting cables," in Proc. 7th ECNDT, European Conf. Non-Destructive Testing, Copenhagen, Denmark, May 26-29, 1998, pp. 1925-1932.

[7] J. Neuenschwander, B. Blau, I. L. Horvath, Th. Lüthi, and H. Marti, "Bond and electron beam welding quality control of the aluminum stabilized and reinforced CMS conductor by means of ultrasonic phasedarray technology," in Proc. 17th Int. Conf. Magnet Technology, Geneva, Switzerland, Sept. 2001, submitted for publication.

[8] M. Greco, P. Fabbricatore, and R. Musenich, "Critical current measurements on the CMS stabilized conductor," IEEE Trans. Appl. Superconduct., submitted for publication. 